I. Exploring the sources of default ernational convergence of capital work. Bank for International Settle-

Isis of high dimensional VARs feaan Central Bank.

of the vector autoregressive model IT 2008: Proceedings in Computa9-501. Physica, Heidelberg.

railty correlated default. Journal of

$\downarrow$ corporate default prediction with is 83, 635-665.

iigration models with application to 188-226.

Education, Upper Saddle River, NJ. lit risk models. The Journal of Credit

sk factor modeling and the Basel II nd Financial Supervision, Deutsche

sting credit event frequency: empirf Risk 9(1), 75-98.

I University Press.

<ing Paper 14, Bank for International

Modeling frailty-correlated defaults Econometrics 162(2), 312-325.

A. (2009). Credit cycles and macro $-54$.

ie Series Analysis. Springer.

,ries Econometrics. Cambridge Uni-

Neiner, S. (2006). Macroeconomic ırnal of Money, Credit and Banking

\section{Empirical performance of loss given default prediction models}

\section{Benjamin Bade}

Institute of Banking and Finance, Leibniz University of Hannover, Königsworther Platz 1, 30167 Hannover, Germany; email: benjamin.bade@finance.uni-hannover.de

\section{Daniel Rösch}

Institute of Banking and Finance, Leibniz University of Hannover, Königsworther Platz 1, 30167 Hannover, Germany; email: daniel,roesch@finance.uni-hannover.de

\section{Harald Scheule}

Department of Finance, Faculty of Business and Economics, University of Melbourne, Victoria 3010, Australia; email: hscheule@unimelb.edu.au

\begin{abstract}
The global financial crisis highlighted the fact that default and recovery rates of multiple borrowers generally deteriorate jointly during economic downturns. The vast majority of the literature, as well as many industry credit-portfolio risk models, ignore this and analyze default probabilities and recoveries in the event of default separately. As a result, the models project losses that are too low in economic downturns such as the recent financial crisis. Nevertheless, alternatives that incorporate the dependence between probabilities of default and recovery rates have been proposed. This paper is the first of its kind to assess the performance of these structurally different approaches. Four banks using different estimation procedures are compared. We use root mean square errors and relative absolute errors to measure the predictive accuracy of each procedure. The results show that models accounting for the correlation of default and recovery do indeed perform better than models ignoring it.
\end{abstract}

\section{INTRODUCTION}

Calculating an accurate measurement of the credit risk underlying defaultable obligations such as loans or bonds is probably one of the most challenging tasks involved in

The authors gratefully acknowledge the support of the Australian Centre for Financial Studies, the Frankfurt Institute for Risk Management and Regulation, the Hong Kong Institute for Monetary Research and the Thyssen Krupp Foundation. 
the risk management of a financial institution. The trade-off between complying with the Basel capital requirements and the opportunity costs of tying up too much capital makes this task even more challenging. Appropriate models for the probability of a default event (PD), the exposure at the time of default (EAD) and the loss given a default event (LGD) have to be defined and calibrated by empirical data. In particular, the test of modeling PD and LGD deals with a high level of uncertainty.

Looking at the theoretical and empirical realization of this task in theory as well as in practice, several gaps are identifiable. First of all, there is a wide range of literature on analyzing the drivers of either PD (see, for example, Leland (1994); Jarrow and Turnbull (1995); Longstaff and Schwartz (1995); Madan and Unal (1995); Leland and Toft (1996); Jarrow et al (1997); Duffie and Singleton (1999); Shumway (2001); McNeil and Wendin (2007); and Duffie et al (2007)) or LGD (see, for example, Carey (1998); Citron et al (2003); Dermine and de Carvalho (2006); Acharya et al (2007); Altman (2009); Qi and Yang (2009); Grunert and Weber (2009); and Calabrese and Zenga (2010)). Many industry credit-portfolio risk models are also based on isolated modules for default probabilities and recoveries in the event of default. In contrast, approaches to joint modeling and estimation are scarce (exceptions are, for example, Pykhtin (2003); Rösch and Scheule (2005); Kupiec (2008); Bruche and GonzálezAguado (2010); and Rösch and Scheule (2010)), although empirical data shows that default and recovery rates jointly deteriorate during economic downturns. Figure 1 on the facing page highlights this stylized fact for the recession years 1990 and 1991 (the time of the Persian Gulf War), 2001 and 2002 (the period following the September 11,2001 terrorist attacks and the general downturn in the US technology industry) as well as 2008 and 2009 (the global financial crisis).

Bade et al (2011) provide empirical evidence that default process and recovery process are indeed highly correlated by applying US nonfinancial corporate bond data to an econometric extension of the economic model introduced by Pykhtin (2003).

The second gap in the literature is performance comparisons among the several different approaches to PD and LGD forecasting. Besides the most recent contribution of Qi and Zhao (2011), one exception is Bastos (2010), who compares simple ordinary least squares (OLS) estimation procedures of LGD with a nonparametric regression tree approach on the basis of root mean squared errors (RMSEs) and relative absolute errors (RAEs). Nevertheless, the authors of both papers use data solely from defaulted obligations, as do their predecessors from this strand of literature (see, for example, Bellotti and Crook (2007) and Caselli et al (2008)).

This paper addresses these weaknesses by comparing predictions derived from the model by Bade et al (2011) with a quick and dirty mean prediction, a simple OLS model and a model incorporating a perfect correlation between default and recovery process as proposed by Rösch and Scheule (2009). Following Bastos (2010) we do this by calculating RMSEs and RAEs for the recovery rate estimates of defaulted bonds.

The Journal of Risk Model Validation

\section{FIGURE 1 Default rates and ।}

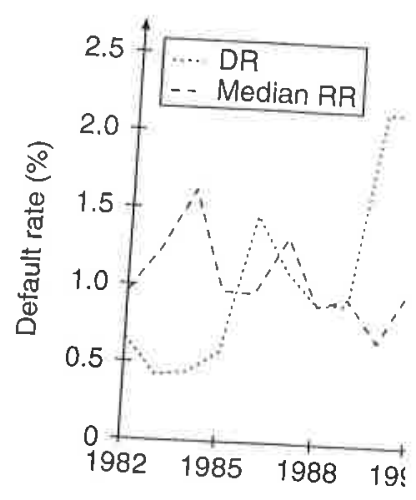

This figure shows that default and recovery ratio of defaulted bond issues to total bond debt obligations thirty days after the occuri detailed description of the data, see Sectior

In addition, we apply these me between portfolio default rate a expected loss (EL).

The paper proceeds as follows. ing their estimation and the calcul on the derived parameter estimate: framework of our analysis. The res the paper.

\section{THEORETICAL FRAMEW} 2.1 The general default and Generally, we assume that the defar value period $t\left(i=1, \ldots, N_{t}, t=1\right.$ value return $V_{i t}$ as introduced by $N$
value return, specified by:

$$
V_{i t}=
$$

crosses a threshold, generally assu factors that infleterministic firm-sF Research paper 
trade-off between complying with costs of tying up too much capital tte models for the probability of :fault (EAD) and the loss given. ed by empirical data. In particular $x$ level of uncertainty.

on of this task in theory as well as there is a wide range of literature mple, Leland (1994); Jarrow and Madan and Unal (1995); Leland 'gleton (1999); Shumway (2001); or LGD (see, for example, Carey ho (2006); Acharya et al (2007); Veber (2009); and Calabrese and nodels are also based on isolated the event of default. In contrast, rce (exceptions are, for example, : (2008); Bruche and Gonzálezhough empirical data shows that conomic downturns. Figure 1 on :ession years 1990 and 1991 (the seriod following the September I the US technology industry) as

it default process and recovery onfinancial corporate bond data ntroduced by Pykhtin (2003). omparisons among the several les the most recent contribution who compares simple ordinary ith a nonparametric regression (RMSEs) and relative absolute ; use data solely from defaulted of literature (see, for example,

$g$ predictions derived from the ean prediction, a simple OLS between default and recovery wing Bastos (2010) we do this estimates of defaulted bonds.
FIGURE 1 Default rates and recovery rates of nonfinancial bond issues 1982-2009.

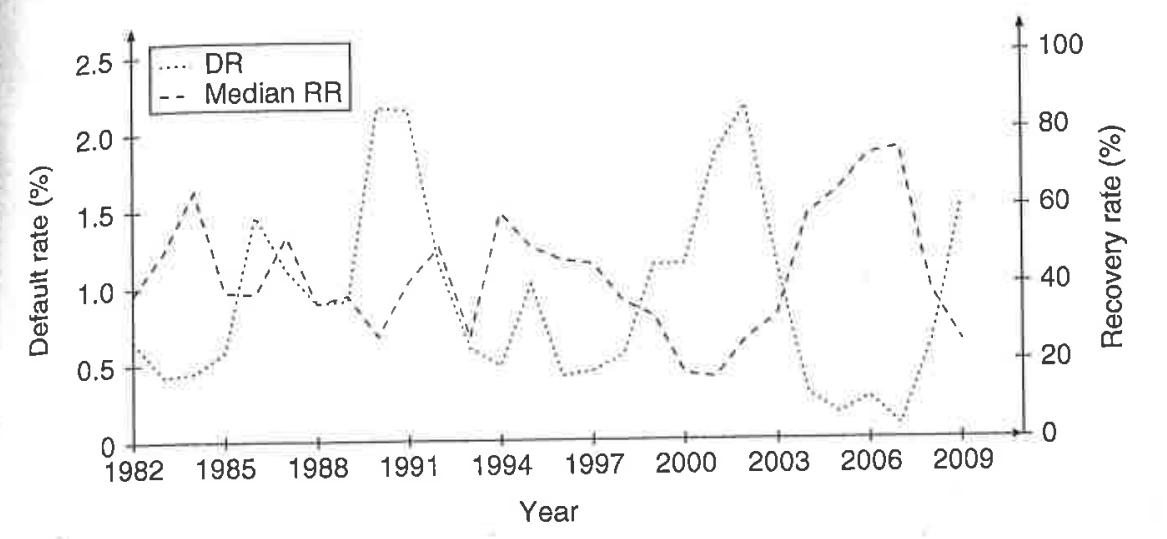

This figure shows that default and recovery rates vary over time and are negatively correlated. The default rate is the

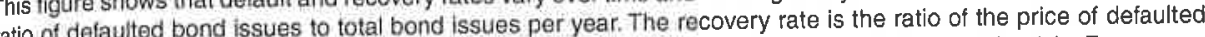
debt obligations thirty days after the occurrence of a default event to the par value. Source: Moody's. For a more detalled description of the data, see Section 3

In addition, we apply these measures to the portfolio level: namely, the difference between portfolio default rate and PD as well as between portfolio loss rate and expected loss (EL).

The paper proceeds as follows. Section 2 briefly introduces the models used, including their estimation and the calculation procedures of the required risk measures based on the derived parameter estimates. In Section 3 we describe the empirical data and the framework of our analysis. The results are presented in Section 4 . Section 5 concludes the paper.

\section{THEORETICAL FRAMEWORK}

\subsection{The general default and recovery process specification}

Generally, we assume that the default process of a single borrower or bond issuer $i$ in time period $t\left(i=1, \ldots, N_{t}, t=1, \ldots, T\right)$ is driven by a normally distributed asset value return $V_{i t}$ as introduced by Merton (1974). A default event occurs if the asset value return, specified by:

$$
V_{i t}=\beta_{0}+\beta^{\prime} x_{i t}^{V}+Z_{i t}^{V}
$$

crosses a threshold, generally assumed to be zero. $x_{i t}^{V}=\left(x_{i t 1}^{V}, \ldots, x_{i t K}^{V}\right)^{\prime}$ are $K$ observable and deterministic firm-specific, industry-specific or macroeconomic risk factors that influence the asset value return. $\beta=\left(\beta_{1}, \ldots, \beta_{K}\right)^{\prime}$ are the sensitivities 
with respect to these factors and $\beta_{0}$ is a constant. $Z_{i t}^{V}$ is an idiosyncratic independent and identically distributed $N \sim(0,1)$ random variable driving the return of borrower $i$ 's assets in time period $t$.

Following Bade et al (2011) we specify the recovery process by:

$$
Y_{i t}=\gamma_{0}+\gamma^{\prime} x_{i t}^{Y}+\sigma \rho^{U} Z_{i t}^{V}+\sigma \sqrt{1-\left(\rho^{U}\right)^{2}} Z_{i t}^{Y}
$$

where $Y_{i t}$ is the logarithm of the recovery rate and is thus interpretable as (potential) return on the debt amount outstanding. $x_{i t}^{Y}=\left(x_{i t 1}^{Y}, \ldots, x_{i t L}^{Y}\right)^{\prime}$ are $L$ deterministic observable risk factors driving the recovery, $\gamma=\left(\gamma_{1}, \ldots, \gamma_{L}\right)^{\prime}$ represent the loadings of these factors, and $\gamma_{0}$ is a constant. $Z_{i t}^{Y}$ is independent and identically distributed $N \sim(0,1)$ and $\sigma$ is a constant parameter. Yet, since $Z_{i t}^{V}$ is part of (2.1) and (2.2), the parameter $\rho^{U}$ is the correlation between both firm-specific errors as well as the conditional correlation between the asset return and the log-recovery process given the observable covariates.

Besides the possible correlation of the default process and the recovery process introduced in the model presented above, the second feature we would like to introduce is that, in general, the recovery rate of a debt obligation is only observable in the case of default. In order to account for this fact, Bierens (2007) derives a maximum likelihood procedure to simultaneously estimate the parameters for such a statistical model firstly introduced by Heckman (1979). The log-likelihood for a single observation $i$ in period $t$ takes the following form:

$$
\begin{aligned}
\mathscr{L}_{i t}=(1 & \left.-d_{i t}\right) \ln \Phi\left(\beta_{0}+\beta^{\prime} x_{i t}^{V}\right)+d_{i t} \ln \left(1-\Phi\left(\beta_{0}+\beta^{\prime} x_{i t}^{V}\right)\right) \\
& +d_{i t} \ln \frac{\phi\left(\left(y_{i t}-\left(\gamma_{0}+\gamma^{\prime} x_{i t}^{Y}\right)\right) / \sigma\right)}{\sigma\left(1-\Phi\left(\beta_{0}+\beta^{\prime} x_{i t}^{V}\right)\right)} \\
& +d_{i t} \ln \left(1-\Phi\left[\frac{\left(\rho^{U} / \sigma\right)\left(y_{i t}-\left(\gamma_{0}+\gamma^{\prime} x_{i t}^{Y}\right)\right)+\left(\beta_{0}+\beta^{\prime} x_{i t}^{V}\right)}{\sqrt{1-\left(\rho^{U}\right)^{2}}}\right]\right)
\end{aligned}
$$

$\phi(\cdot)$ specifies the density function and $\Phi(\cdot)$ the cumulative distribution function of the standard normal distribution. $d_{i t}$ indicates whether the observed obligation defaults $\left(d_{i t}=1\right)$ or not $\left(d_{i t}=0\right)$. Thus, all parameters may be estimated without the knowledge of values for $V_{i t}$. Equation (2.3) is then maximized over $n_{t}$ observations per period and $T$ periods:

$$
\ell=\sum_{t=1}^{T} \sum_{i=1}^{n_{t}} \mathcal{L}_{i t}
$$

\subsection{Model assumptions and consequences}

For the general framework presented above two restrictive assumptions are of particular interest. The first one is the assumption that, conditional on given realizations of

The Journal of Risk Model Validation the observable risk factors, the observed log-recoveries the next page). The assump tion of the parameters unde to:

$$
\mathcal{L}_{i t}^{\text {uncorr }}=\underbrace{\left(1-d_{i t}\right) \ln \Phi(1}
$$

The parameters of $\mathcal{L}_{i t}^{\text {probit }}$ are likelihood (see, for example, and Hamerle et al (2003)):

Due to the independence of thi eters of $\mathcal{L}_{i t}^{\text {recovery }}$ need not ne convenience, a simple OLS re

The second possible restricti processes are perfectly positivt as $\beta=\gamma / \sigma$. In other-words, br ables and each variable has the the default barrier translates int distribution equals a truncated 1 the next page).

The log-likelihood for a sing log-likelihood of a Tobit model

$$
\mathcal{L}_{i t}^{\text {Tobit }}=\left(1-d_{i t}^{\text {Tobit }}\right) \ln \Phi\left(\underline{\gamma_{1}}\right.
$$

Please note that many other transf

possible (see, for example, Dermine ar

that results are comparable to the unr

${ }^{2}$ For the derivation of such a likelihor defaults and recoveries, see Rösch an 
${ }_{t}$ is an idiosyncratic independent ble driving the return of borrower 'ery process by:

$\sqrt{1-\left(\rho^{U}\right)^{2}} Z_{i t}^{Y}$

; thus interpretable as (potential) $\left., \ldots, x_{i t L}^{Y}\right)^{\prime}$ are $L$ deterministic $\left., \ldots, \gamma_{L}\right)^{\prime}$ represent the loadings ident and identically distributed e $Z_{i t}^{V}$ is part of (2.1) and (2.2) m-specific errors as well as the the log-recovery process given

ocess and the recovery process ature we would like to introduce is only observable in the case of ) derives a maximum likelihood or such a statistical model firstly a single observation $i$ in period

$\left.\left.3_{0}+\beta^{\prime} x_{i t}^{V}\right)\right)$

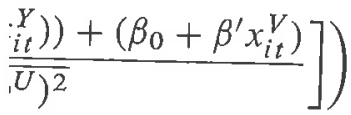

ive distribution function of the z observed obligation defaults nay be estimated without the uximized over $n_{t}$ observations

ive assumptions are of particional on given realizations of the observable risk factors, both processes are uncorrelated, ie, $\rho^{U}=0$. In this case the observed log-recoveries are normally distributed (see the dark bars in Figure 2 on the next page). The assumption of uncorrelated error terms allows a separate estimation of the parameters underlying both processes in the model, since $\mathscr{L}_{i t}$ simplifies to:

$$
\begin{aligned}
\mathcal{L}_{i t}^{\text {uncorr }}=\underbrace{\left(1-d_{i t}\right) \ln \Phi\left(\beta_{0}+\beta^{\prime} x_{i t}^{V}\right)}_{\mathcal{L}_{i t}^{\text {probit }}}+d_{i t} \ln \left(1-\Phi\left(\beta_{0}+\beta^{\prime} x_{i t}^{V}\right)\right) \\
+\underbrace{d_{i t} \ln \frac{\phi\left(\left(y_{i t}-\left(\gamma_{0}+\gamma^{\prime} x_{i t}^{Y}\right)\right) / \sigma\right)}{\sigma}}_{\mathcal{L}_{i t}^{\text {recovery }}}
\end{aligned}
$$

The parameters of $\mathcal{L}_{i t}^{\text {probit }}$ are estimated by a standard probit procedure via maximum likelihood (see, for example, Gordy and Heitfield (2000); Gordy and Heitfield (2002); and Hamerle et al (2003)):

$$
\ell^{\text {probit }}=\sum_{t=1}^{T} \sum_{i=1}^{n_{t}} \mathcal{L}_{i t}^{\text {probit }}
$$

Due to the independence of the recovery process from the default process, the parameters of $\mathcal{L}_{i t}^{\text {recovery }}$ need not necessarily be estimated via maximum likelihood. For convenience, a simple OLS regression of the observed log-recoveries may be run. ${ }^{1}$

The second possible restrictive assumption to the model is that default and recovery processes are perfectly positively correlated, ie, $\rho^{U}=1$, and that $\beta_{0}=\gamma_{0} / \sigma$ as well as $\beta=\gamma / \sigma$. In other words, both processes are driven by the same explanatory variables and each variable has the same standardized exposure in both processes. Thus, the default barrier translates into a cutoff point for the observed log-recoveries. Their distribution equals a truncated normal distribution (see the lighter bars in Figure 2 on the next page).

The log-likelihood for a single observation under this restriction simplifies to the log-likelihood of a Tobit model: ${ }^{2}$

$$
\mathcal{L}_{i t}^{\text {Tobit }}=\left(1-d_{i t}^{\text {Tobit }}\right) \ln \Phi\left(\frac{\gamma_{0}+\gamma^{\prime} x_{i t}^{Y}}{\sigma}\right)+d_{i t}^{\text {Tobit }} \ln \frac{\phi\left(\left(y_{i t}-\left(\gamma_{0}+\gamma^{\prime} x_{i t}^{Y}\right)\right) / \sigma\right)}{\sigma}
$$

${ }^{1}$ Please note that many other transformations of the recovery rates, such as logit or probit, are possible (see, for example, Dermine and de Carvalho (2006) or Bastos (2010)), but in order to ensure that results are comparable to the unrestricted model we focus on the logarithmic transformation. ${ }^{2}$ For the derivation of such a likelihood, see Bierens (2004). For an empirical application for bond defaults and recoveries, see Rösch and Scheule (2009). 
FIGURE 2 Distributions of observable log-recoveries for a sample portfolio of 100000 obligors and differently correlated error terms.

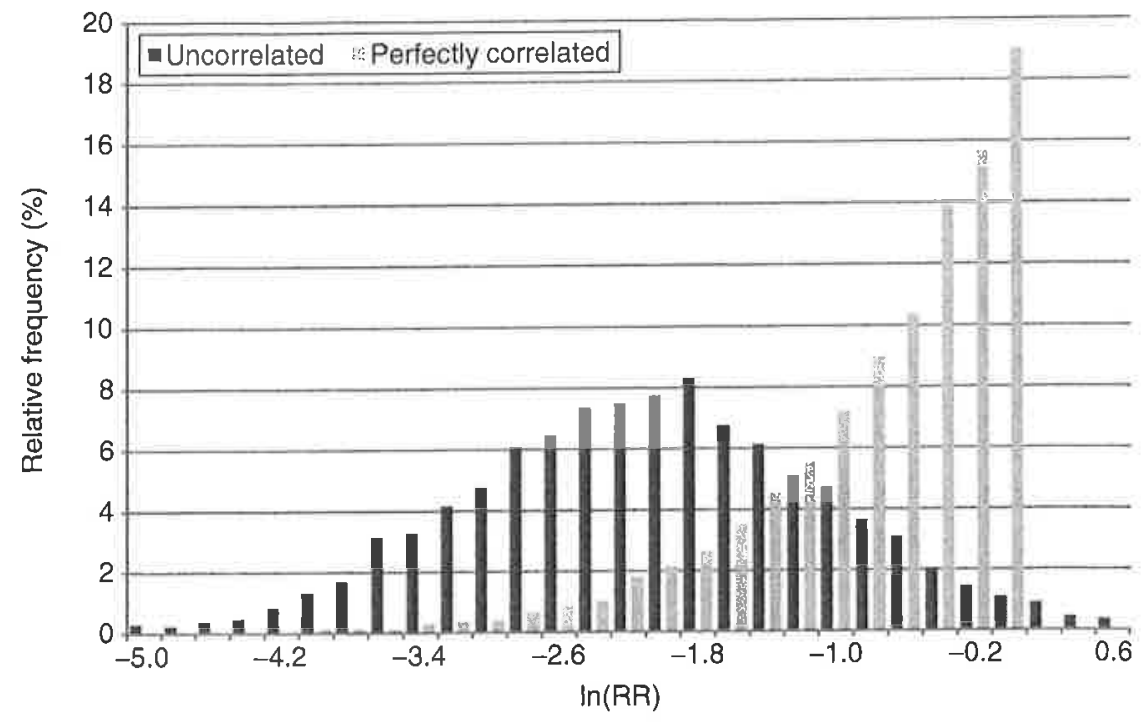

This figure presents distributions of log-recoveries for defaulted obligors in a sample portfolio of 100000 obligors under different assumptions concerning the correlation between default and recovery process. The underlying parameters of the simulation for uncorrelated error terms (dark bars), ie, $\rho^{U}=0$, are $\beta_{0}=1.6449$ (which corresponds to a PD of $5 \%$ ), $\gamma_{0}=-2.3551$ and $\sigma=1$. The underlying parameters of the simulation for perfectly correlated error terms (light bars), ie, $\rho^{U}=1$, are $\beta_{0}=1.6449$ (which corresponds to a PD of $5 \%$ ), $\gamma_{0}=2.46735$ and $\sigma=1.5$.

Since the default barrier is generally assumed to be zero, the truncation of the logrecoveries is made at zero too. Nevertheless, real data may contain recovery rates greater than 1 , ie, log-recoveries greater than 0 . These observations should be treated as nondefaults, such that $d_{i t}^{\text {Tobit }} \neq d_{i t}$ in these cases. The maximum likelihood function is:

$$
\ell^{\text {Tobit }}=\sum_{t=1}^{T} \sum_{i=1}^{n_{t}} \mathcal{L}_{i t}^{\text {Tobit }}
$$

\subsection{Calculation of risk measures}

In order to predict the risk of a debt obligation, the parameters derived by the methods presented above are only of secondary interest. The primary risk measures of impor tance are the PD, the EL and the recovery rate in the case where such an obligation defaults (expected recovery given default (ERGD)). Generally, these three ratios are linked by:

$$
\mathrm{ERGD}_{i t}=1-\frac{\mathrm{EL}_{i t}}{\mathrm{PD}_{i t}}
$$

The Journal of Risk Model Validation
Since we assume an ass, the probability that $V_{i t}$ fall: normality assumption, we $\mathrm{c}$

For EL and ERGD, resp default and recovery process estimates of (2.4) are used to

$$
\begin{array}{r}
\mathrm{EL}_{\text {it }}^{\text {general }}=\Phi_{2}\left[-\left(\beta_{0}+1\right.\right. \\
-\exp \left(\gamma_{0}+\right) \\
\quad \times \Phi_{2}[-
\end{array}
$$

$\Phi_{2}[\cdot, \cdot, \cdot]$ represents the distrib the more restrictive case of unc the expected recovery given de the parameter estimates of (2.t of the recovery process with log simple OLS, ERGD is calculate

$$
\mathrm{ERGD}_{i t}^{\mathrm{O}}
$$

With the parameters derived und obtain EL by:

$$
\mathrm{EL}_{i t}^{\text {Tobit }}=\Phi\left(-\frac{\gamma_{0}+\gamma^{\prime} x_{i t}^{Y}}{\sigma}\right)-
$$

Please note that in the Tobit case 1

$$
\mathrm{PD}_{i t}^{\text {Tobit }}
$$

\section{DATA AND METHODOLOC COMPARISON}

3.1

$$
\begin{aligned}
& 3.1 \text { Default and recovery dai } \\
& \text { The data sample underlying the en } \\
& \text { rating agency and is the same as tI } \\
& \text { Research Paper }
\end{aligned}
$$


a sample portfolio of 100000

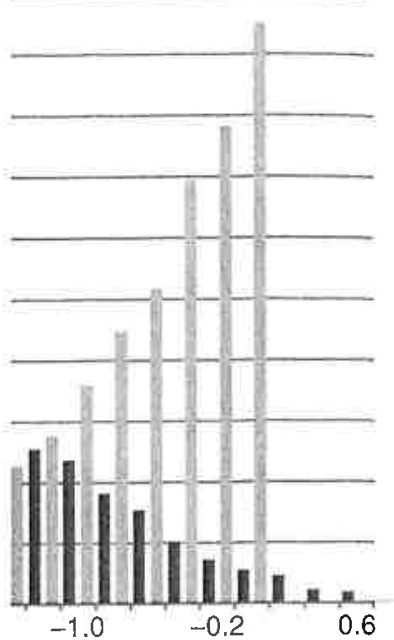

a sample portfolio of 100000 obligors ecovery process. The underlying paramare $\beta_{0}=1.6449$ (which corresponds to simulation for perfectly correlated error 1 of $5 \%), \gamma_{0}=2.46735$ and $\sigma=1.5$.

ro, the truncation of the logmay contain recovery rates bservations should be treated naximum likelihood function

jeters derived by the methods nary risk measures of imporise where such an obligation nerally, these three ratios are
Since we assume an asset value process for the default event, the PD is given as the probability that $V_{i t}$ falls below zero (given the observable covariates). Under the normality assumption, we obtain:

$$
\mathrm{PD}_{i t}=1-\Phi\left(\beta_{0}+\beta^{\prime} x_{i t}^{V}\right)
$$

For EL and ERGD, respectively, the assumptions concerning the link between default and recovery process have to be considered. In the general case the parameter estimates of (2.4) are used to calculate the expected loss by:

$$
\begin{aligned}
\mathrm{EL}_{i t}^{\text {general }}=\Phi_{2}[- & \left.\left(\beta_{0}+\beta^{\prime} x_{i t}^{V}\right),-\frac{\gamma_{0}+\gamma^{\prime} x_{i t}^{Y}}{\sigma}, \rho^{U}\right] \\
- & \exp \left(\gamma_{0}+\gamma^{\prime} x_{i t}^{Y}+\frac{1}{2} \sigma^{2}\right) \\
& \times \Phi_{2}\left[-\left(\beta_{0}+\beta^{\prime} x_{i t}^{V}\right)-\sigma \rho^{U},-\frac{\gamma_{0}+\gamma^{\prime} x_{i t}^{Y}}{\sigma}-\sigma, \rho^{U}\right]
\end{aligned}
$$

$\Phi_{2}[\cdot, \cdot, \cdot]$ represents the distribution function of the bivariate normal distribution. For the more restrictive case of uncorrelated error terms it is most convenient to calculate the expected recovery given default first and the expected loss afterward by applying the parameter estimates of (2.6) to the PD and rearranging (2.9). If the parameters of the recovery process with log-recoveries as a dependent variable are estimated by simple OLS, ERGD is calculated by:

$$
\mathrm{ERGD}_{i t}^{\mathrm{OLS}}=\exp \left(\gamma_{0}+\gamma^{\prime} x_{i t}^{Y}+0.5\right)
$$

With the parameters derived under the assumptions of the Tobit approach in (2.7) we obtain EL by:

$\mathrm{EL}_{i t}^{\text {Tobit }}=\Phi\left(-\frac{\gamma_{0}+\gamma^{\prime} x_{i t}^{Y}}{\sigma}\right)-\exp \left(\gamma_{0}+\gamma^{\prime} x_{i t}^{Y}+0.5 \sigma^{2}\right) \Phi\left(-\frac{\gamma_{0}+\gamma^{\prime} x_{i t}^{Y}+\sigma^{2}}{\sigma}\right)$

Please note that in the Tobit case the PD is computed as:

$$
\operatorname{PD}_{i t}^{\text {Tobit }}=\Phi\left(-\frac{\gamma_{0}+\gamma^{\prime} x_{i t}^{Y}}{\sigma}\right)
$$

\section{DATA AND METHODOLOGY OF THE PERFORMANCE COMPARISON}

\subsection{Default and recovery data}

The data sample underlying the empirical analysis is provided by Moody's credit rating agency and is the same as the one used by Bade et al (2011). The data set 
TABLE 1 Number of observations, default rate and mean recovery.

\begin{tabular}{|c|c|c|c|c|c|c|}
\hline Rating & $N_{\text {obs }}$ & $\begin{array}{c}\text { Percentage } \\
\text { of all } \\
\text { observations }\end{array}$ & $N_{\text {def }}$ & $\begin{array}{c}\text { Percentage } \\
\text { of all } \\
\text { default } \\
\text { observations }\end{array}$ & DR & $\mathrm{RRGD}_{\emptyset}$ \\
\hline IG & 146582 & 78.120 & 51 & 3.074 & 0.035 & 46.823 \\
\hline $\mathrm{Ba}$ & 15262 & 8.134 & 87 & 5.244 & 0.570 & 48.607 \\
\hline$B$ & 20132 & 10.729 & 530 & 31.947 & 2.633 & 39.890 \\
\hline$C$ & 5662 & 3.018 & 991 & 59.735 & 17.503 & 34.836 \\
\hline Total & 187638 & 100.000 & 1659 & 100.000 & 0.884 & 37.541 \\
\hline
\end{tabular}

This

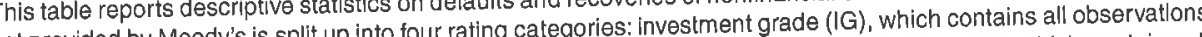
set provided by Moody's is split up into four rating categores. Ina; a rating of $\mathrm{B}$; and a rating of $\mathrm{C}$, which contains all with a Moody's rating higher than Ba; those with a rating of Ba; a rating of $\mathrm{B}$; and a rating $N_{\text {der }}$ is the number of defaults. observations with a Moody's rating lower than B. $N_{\text {obs }}$ is the number of observations, $N_{\text {der }}$ is the number of default DR (default rate) is the ratio of the number of defaults to the number of observations in each rating grade. RR is the mean recovery rate of the defaulted bonds in each ralling of a default event to par value.

contains the annual ratings of regular US bond issues, as well as default dates and recovery rates given default. Moody's records a default event if interest or principal payments are missed or delayed, Chapter 11 or Chapter 7 bankruptcy is filed or a distressed exchange, such as a reduction in a financial obligation, occurs. The recovery rate is equal to the price of a defaulted bond measured thirty days after a default event in relation to the face value of the bond.

Table 1 summarizes important descriptive statistics for the data set, which consists of 187638 observations for regular US bond issues of nonfinancial institutions from 1982 to 2009. Coincident with a change in Moody's rating methodology in 1982 and the role of ratings in the subsequent analysis, earlier observations are excluded from this empirical study.

During the observation period, a total of 1659 defaults occurred, which yields a default rate (DR) of $0.884 \%$. The mean recovery rate for all defaulted bonds is $37.541 \%$; the median recovery rate is $32 \%$.

Table 1 also shows the descriptive statistics per rating category: all bond issues with a rating higher than $\mathrm{Ba}$ are aggregated to an investment grade (IG) rating, and all bond issues with a rating lower than $\mathrm{B}$ are aggregated to rating $\mathrm{C}$. This categorization addresses the limited number of default events in the subcategories. The table shows that, as one may expect, the default rate increases from rating IG to $C$. The mean recovery rate decreases from rating IG to C, except for grades Ba (48.607\%) and IG $(46.823 \%)$, which may be due to the small number of defaults, and hence the small number of recovery events in both grades.

Since the rating grade as well as the rating shift in the year prior to the observed rating status $\left(\right.$ rating $_{i t}-$ rating $_{i t-1}$ ) are statistically and economically significant for the data set, we include rat shift as explanatory variabl.

In order to account for the in Figure 1 on page 27, we ir variable in the study.

Since all explanatory vari: quantities when predicting $\mathrm{F}$

\subsection{Model validation $\mathrm{fr}$}

In the empirical study we c projection of future defaults

- Bank 1 simply estimat probably the most conv predicting future defau

- Bank 2 follows the res the probit approach of industry-specific and $n$ marginal effect of each ، regard to LGD forecasts arithm of the recovery $\mathrm{r}$ :

- Bank 3 uses the Tobit ap the historical data.

- Bank 4 uses the general simultaneously.

In detail, the model validatior of five steps, which are repeatec

- Step 1: we select $90 \%$ of $10 \%$ of the data as out-of.

${ }^{3}$ Since, for bonds originated in the ye: (MV), we include a dummy variable obrough this, we are able to keep th: servations with rating $i_{i t}-$ rating $_{i t-}$ Rosearch Paper 
recovery.

\begin{tabular}{lrr} 
Ige & & \\
$\mathbf{t}$ & & \\
ons & DR & RRGD $_{\emptyset}$ \\
\hline 4 & 0.035 & 46.823 \\
4 & 0.570 & 48.607 \\
7 & 2.633 & 39.890 \\
5 & 17.503 & 34.836 \\
0 & 0.884 & 37.541 \\
\hline
\end{tabular}

cial bonds from 1982 to 2009. The data te (IG), which contains all observations $B$; and a rating of $C$, which contains all rvations. $N_{\text {der }}$ is the number of defaults. ervations in each rating grade. $R R G D_{\hat{\beta}}$ recovery rate is the ratio of the price of to par value.

as well as default dates and event if interest or principal er 7 bankruptcy is filed or a igation, occurs. The recovery irty days after a default event

Ir the data set, which consists tonfinancial institutions from ng methodology in 1982 and servations are excluded from

zults occurred, which yields te for all defaulted bonds is

ng category: all bond issues zent grade (IG) rating, and all rating $\mathrm{C}$. This categorization bcategories. The table shows $m$ rating $\mathrm{IG}$ to $\mathrm{C}$. The mean grades $\mathrm{Ba}(48.607 \%)$ and $\mathrm{IG}$ lefaults, and hence the small

he year prior to the observed economically significant for the data set, we include rating dummies as well as an ordinal variable for the rating shift as explanatory variables in the empirical study. ${ }^{3}$

In order to account for the time series variation of default and recovery rates shown in Figure 1 on page 27, we include the lagged change of GPDI as a further explanatory variable in the study.

Since all explanatory variables are lagged by one year, they can be treated as known quantities when predicting PD, EL and ERGD.

\subsection{Model validation framework}

In the empirical study we compare four banks with competing approaches to the projection of future defaults and losses:

- Bank 1 simply estimates PD, EL and ERGD by historical averages, which is probably the most convenient but most likely also the least accurate method for predicting future default or recovery rates.

- Bank 2 follows the restrictive approach of (2.5), ie, it estimates the PD with the probit approach of (2.6), which allows an incorporation of firm-specific, industry-specific and macroeconomic covariates and an explanation of the marginal effect of each considered variable on the likelihood of a default. With regard to LGD forecasts, Bank 2 uses an OLS regression with the natural logarithm of the recovery rate of defaulted bonds as dependent variable.

- Bank 3 uses the Tobit approach of (2.7) to obtain the relevant parameters from the historical data.

- Bank 4 uses the general Heckman approach of (2.3) to forecast PD and LGD simultaneously.

In detail, the model validation framework for our performance comparison consists of five steps, which are repeated 10000 times in order to exclude sample effects:

- Step 1: we select $90 \%$ of the data as a random sample and treat the remaining $10 \%$ of the data as out-of-sample.

${ }^{3}$ Since, for bonds originated in the year of observation, rating ${ }_{i t}-$ rating $_{i t-1}$ yields a missing value (MV), we include a dummy variable for these observations and set rating $i t-$ rating $_{i t-1}=0$. Through this, we are able to keep these observations in the data set and differentiate between observations with rating $i t-$ rating $_{i t-1}=0$ and rating it - rating $_{i t-1}=\mathrm{MV}$.

www.journalofriskmodelvalidation.com 
TABLE 2 Results for RMSE on the recovery rate level.

(a) MMSE$_{\mathrm{RR}}^{\mathrm{in}-\mathrm{sample}}$

\begin{tabular}{ccccc}
\hline Specification & Bank 1 & Bank 2 & Bank 3 & Bank 4 \\
\hline 1 & 0.28623 & 0.27280 & 0.26855 & 0.26632 \\
& $(0.00060)$ & $(0.00130)$ & $(0.00126)$ & $(0.00134)$ \\
2 & 0.28623 & 0.27281 & 0.26821 & 0.26592 \\
& $(0.00059)$ & $(0.00130)$ & $(0.00123)$ & $(0.00133)$ \\
\multirow{2}{*}{3} & 0.28623 & 0.27231 & 0.26864 & 0.26553 \\
& $(0.00060)$ & $(0.00133)$ & $(0.00127)$ & $(0.00137)$ \\
\multirow{2}{*}{4} & 0.28623 & 0.27224 & 0.26833 & 0.26520 \\
& $(0.00060)$ & $(0.00134)$ & $(0.00126)$ & $(0.00138)$ \\
\hline
\end{tabular}

(b) RMSE

\begin{tabular}{ccccc}
\hline Specification & Bank 1 & Bank 2 & Bank 3 & Bank 4 \\
\hline \multirow{2}{*}{1} & 0.28633 & 0.27380 & 0.26842 & 0.26665 \\
& $(0.01386)$ & $(0.01195)$ & $(0.01167)$ & $(0.01258)$ \\
\multirow{2}{*}{2} & 0.28631 & 0.27402 & 0.26808 & 0.26636 \\
& $(0.01394)$ & $(0.01152)$ & $(0.01141)$ & $(0.01241)$ \\
\multirow{2}{*}{3} & 0.28629 & 0.27373 & 0.26851 & 0.26617 \\
& $(0.01406)$ & $(0.01202)$ & $(0.01171)$ & $(0.01281)$ \\
\multirow{2}{*}{4} & 0.28630 & 0.27388 & 0.26823 & 0.26598 \\
& $(0.01413)$ & $(0.01218)$ & $(0.01167)$ & $(0.01279)$ \\
\hline
\end{tabular}

RMSE is calculated by (3.1). Standard deviations are reported in parentheses.

- Step 2: with the in-sample data we estimate the relevant parameters of the models underlying the banks' prediction techniques. For each model, we investigate four different specifications containing the following explanatory variables.

- Specification 1: ratings.

- Specification 2: ratings and lagged GPDI change.

- Specification 3: ratings and rating shift.

- Specification 4: ratings, rating shift and lagged GPDI change.

- Step 3: these parameters are incorporated to estimate PD, ERGD and EL for each observation of the in-sample data set as well as for the out-of-sample data set.
- Step 4: on the sin and compare the 1 $j=1, \ldots, n_{t}^{\text {def }}$, it

$$
\mathrm{RMSE}_{\mathrm{RR}}=
$$

and RAE:

$$
\mathrm{RAE}_{\mathrm{RR}}
$$

RMSE measures the measures the accurac use the arithmetic me the corresponding rat

- Step 5: on the portfoli in both subsamples to

and:

Since we only get one value pe realized portfolio default rate at RMSE and RAE over the 100 do this for the out-of-sample $p$

\section{RESULTS}

\subsection{Single borrower level}

Table 2 on the facing page show and specification. On average, thi the arithmetic mean of observec in-sample as well as out-of-samp Pesearch Paper 
- Step 4: on the single borrower level we follow the approach by Bastos (2010) and compare the realized recovery rates of the defaulted bonds $\mathrm{RR}_{j t}$, where $j=1, \ldots, n_{t}^{\text {def }}$, in each data subset with their estimates via RMSE:

$$
\mathrm{RMSE}_{\mathrm{RR}}=\sqrt{\left(\sum_{t=1}^{T} n_{t}^{\mathrm{def}}\right)^{-1} \sum_{t=1}^{T} \sum_{j=1}^{n_{t}^{\mathrm{def}}\left(\mathrm{RR}_{j t}-\mathrm{ERGD}_{j t}^{\mathrm{model}}\right)^{2}}}
$$

and RAE:

$$
\mathrm{RAE}_{\mathrm{RR}}=\frac{\sum_{t=1}^{T} \sum_{j=1}^{n_{j}^{\mathrm{def}}}\left|\mathrm{RR}_{j t}-\mathrm{ERGD}_{j t}^{\text {model }}\right|}{\sum_{t=1}^{T} \sum_{j=1}^{n_{l}^{\mathrm{def}}}\left|\mathrm{RR}_{j t}-\mathrm{ERGD}_{j t}^{\text {simple }}\right|} \cdot 100
$$

RMSE measures the accuracy of the estimates in absolute terms while RAE measures the accuracy relative to a benchmark estimator. For convenience we use the arithmetic mean of the realized recovery rates calculated by Bank 1 for the corresponding rating grade of each observation as a simple predictor.

- Step 5: on the portfolio level we aggregate the PDs and ELs of the borrowers in both subsamples to portfolio PDs and ELs by:

$$
\mathrm{PD}^{\mathrm{PF}}=\left(\sum_{t=1}^{T} n_{t}\right)^{-1} \sum_{t=1}^{T} \sum_{i=1}^{n_{t}} \mathrm{PD}_{i t}
$$

and:

$$
\mathrm{EL}^{\mathrm{PF}}=\left(\sum_{t=1}^{T} n_{t}\right)^{-1} \sum_{t=1}^{T} \sum_{i=1}^{n_{t}} \mathrm{EL}_{i t}
$$

elevant parameters of the modFor each model, we investigate ,wing explanatory variables.

change.

tgged GPDI change.

stimate PD, ERGD and EL for well as for the out-of-sample
Since we only get one value per risk measure and portfolio that is compared with the realized portfolio default rate and portfolio loss rate, respectively, we have to calculate RMSE and RAE over the 10000 iterations of this random sampling procedure. We do this for the out-of-sample portfolio.

\section{RESULTS}

\subsection{Single borrower level}

Table 2 on the facing page shows the RMSEs in-sample and out-of-sample by bank and specification. On average, the least accurate predictive power is reached by using the arithmetic mean of observed recovery rates (Bank 1) as a forecast for ERGD in-sample as well as out-of-sample. Despite the highest average RMSE, the standard 
TABLE 3 Results for RAE on the recovery rate level.

TABLE 4 Robustness check r

(a) RAE $E_{\text {in }}^{\text {inample }}$

\begin{tabular}{cccccc}
\hline Specification & Bank 1 & Bank 2 & Bank 3 & Bank 4 \\
\hline \multirow{2}{*}{1} & 100 & 99.067 & 97.275 & 95.026 \\
& - & $(0.417)$ & $(0.433)$ & $(0.590)$ \\
2 & 100 & 99.121 & 97.121 & 94.897 \\
& \multirow{2}{*}{3} & - & $(0.413)$ & $(0.424)$ & $(0.571)$ \\
& \multirow{2}{*}{4} & - & $(0.418)$ & $(0.437)$ & $(0.605)$ \\
& 100 & 98.376 & 96.841 & 94.240 \\
& & - & $(0.420)$ & $(0.437)$ & $(0.621)$
\end{tabular}

(b) RAE

\begin{tabular}{cccccc}
\hline Specification & Bank 1 & Bank 2 & Bank 3 & Bank 4 \\
\hline \multirow{2}{*}{1} & 100 & 99.657 & 97.477 & 95.323 \\
& - & $(7.272)$ & $(6.525)$ & $(5.712)$ \\
2 & 100 & 99.785 & 97.322 & 95.217 \\
& - & $(7.142)$ & $(6.399)$ & $(5.600)$ \\
\multirow{2}{*}{3} & 100 & 99.114 & 97.070 & 94.654 \\
& - & $(7.236)$ & $(6.451)$ & $(5.537)$ \\
\multirow{2}{*}{4} & 100 & 99.214 & 97.065 & 94.664 \\
& - & $(7.385)$ & $(6.523)$ & $(5.611)$ \\
\hline
\end{tabular}

RAE is calculated by (3.2), Standard deviations are reported in parentheses.

deviation for the in-sample RMSEs of Bank 1 (0.0006) is the lowest of all four banks in each specification. In contrast, the out-of-sample standard deviation of Bank 1's RMSEs is the highest. Thus, Bank 1 not only has the least accurate method to predict future (ie, out-of-sample) recovery rates for defaulted bonds on average, but also the most insecure method.

Using a simple OLS regression and calculating ERGDs on the basis of the regression results yields improved results compared with Bank 1's approach. The RMSES are reduced on average and for the out-of-sample data in standard deviation, too. The more elaborate the model specification, the lower the average $\mathrm{RMSE}_{\mathrm{RR}}^{\mathrm{in}-\mathrm{sample}}$. Out-ofsample, adding GPDI to the regression model, ie, switching from Specification 1 to 2 or from 3 to 4 , reduces the predictive accuracy. With the exception of switching from Specification 1 to 2 for the out-of-sample data, the standard deviation of the RMSES increases with the number of variables taken into account in both subsamples.

\begin{tabular}{cr}
\hline Specification & B \\
\hline 1 & $0 . i$ \\
& $(0.1$ \\
2 & $0 . c^{2}$ \\
& 10.6 \\
3 & $0 . c$ \\
& $0 . c$ \\
4 & 0.2 \\
& 0.0 \\
\end{tabular}

\begin{tabular}{cr}
\hline Specification & Bal \\
\hline 1 & $0.2 \varepsilon$ \\
& 0.01 \\
2 & 0.28 \\
& 0.01 \\
\multirow{2}{*}{3} & 0.28 \\
& 0.01 \\
\multirow{2}{*}{4} & 0.281 \\
& $(0.01 !$ \\
\hline
\end{tabular}

AMSE is calculated by (3.1). Standard devia

The Tobit procedure used by $\mathrm{F}$ compared with Banks 1 and 2. Nev In contrast to Bank 2, the incorpo forecasts; RMSE decreases on ave hand, incorporating the rating shif and thus lowers the predictive pow the average $\mathrm{RMSE}_{\mathrm{RR}}^{\text {out-of-sample }}$ is lor specification.

The Heckman model implement RMSE. The predictive power rises I banks' predictions in-sample and hi; Posoarch Paper 
TABLE 4 Robustness check results for RMSE on the recovery rate level.

\begin{tabular}{ll}
\hline & \\
& \\
\hline nk 3 & Bank 4 \\
\hline 275 & 95.026 \\
$433)$ & $(0.590)$ \\
121 & 94.897 \\
$424)$ & $(0.571)$ \\
856 & 94.271 \\
$437)$ & $(0.605)$ \\
.841 & 94.240 \\
$.437)$ & $(0.621)$ \\
\hline & \\
& \\
\hline nk 3 & Bank 4 \\
\hline .477 & 95.323 \\
$.525)$ & $(5.712)$ \\
.322 & 95.217 \\
$.399)$ & $(5.600)$ \\
.070 & 94.654 \\
$.451)$ & $(5.537)$ \\
.065 & 94.664 \\
$.523)$ & $(5.611)$ \\
\hline & \\
\hline
\end{tabular}

эs.

I is the lowest of all four banks tandard deviation of Bank 1's ast accurate method to predict bonds on average, but also the

jDs on the basis of the regresink 1's approach. The RMSEs in standard deviation, too. The verage RMSE $\mathrm{R}_{\mathrm{R}}^{\mathrm{in} \text {-sample }}$. Out-ofshing from Specification 1 to 2 te exception of switching from ndard deviation of the RMSEs unt in both subsamples. (a) RMSE $E_{\mathrm{RR}}^{\text {in-sample }}$

\begin{tabular}{ccccc}
\hline Specification & Bank 1 & Bank 2 & Bank 3 & Bank 4 \\
\hline 1 & 0.28625 & 0.27267 & 0.26810 & 0.26618 \\
& $(0.00066)$ & $(0.00145)$ & $(0.00143)$ & $(0.00151)$ \\
\multirow{2}{*}{2} & 0.28625 & 0.27251 & 0.26761 & 0.26596 \\
& $(0.00065)$ & $(0.00144)$ & $(0.00142)$ & $(0.00151)$ \\
\multirow{2}{*}{3} & 0.28625 & 0.27167 & 0.26700 & 0.26482 \\
& $(0.00066)$ & $(0.00145)$ & $(0.00145)$ & $(0.00152)$ \\
\multirow{2}{*}{4} & 0.28625 & 0.27152 & 0.26674 & 0.26487 \\
& $(0.00066)$ & $(0.00145)$ & $(0.00143)$ & $(0.00153)$
\end{tabular}

(b) RMSE

\begin{tabular}{ccccc}
\hline Specification & Bank 1 & Bank 2 & Bank 3 & Bank 4 \\
\hline 1 & 0.28638 & 0.27407 & 0.26793 & 0.26649 \\
& $(0.01579)$ & $(0.01324)$ & $(0.01318)$ & $(0.01400)$ \\
2 & 0.28638 & 0.27421 & 0.26746 & 0.26639 \\
& $(0.01566)$ & $(0.01329)$ & $(0.01315)$ & $(0.01390)$ \\
\multirow{2}{*}{3} & 0.28638 & 0.27335 & 0.26685 & 0.26527 \\
& $(0.01582)$ & $(0.01359)$ & $(0.01339)$ & $(0.01416)$ \\
\multirow{2}{*}{4} & 0.28637 & 0.27351 & 0.26658 & 0.26543 \\
& $(0.01553)$ & $(0.01355)$ & $(0.01328)$ & $(0.01396)$ \\
\end{tabular}

RMSE is calculated by (3.1). Standard deviations are reported in parentheses.

The Tobit procedure used by Bank 3 yields a further improvement of the results compared with Banks 1 and 2. Nevertheless, some qualitative differences are apparent. In contrast to Bank 2, the incorporation of GPDI yields more accurate recovery rate forecasts; RMSE decreases on average as well as its standard deviation. On the other hand, incorporating the rating shift increases RMSE as well as its standard deviation and thus lowers the predictive power of the Tobit model for recovery rates. Unusually, the average $R M S E_{\mathrm{RR}}^{\text {out-of-sample }}$ is lower than the average $\mathrm{RMSE}_{\mathrm{RR}}^{\mathrm{in} \text {-sample }}$ for each model specification.

The Heckman model implemented by Bank 4 yields the best results for the average RMSE. The predictive power rises by adding more explanatory variables to the model specification. The standard deviation of RMSE, though, is higher than for the other banks' predictions in-sample and higher than Bank 2's predictions out-of-sample. Due 
TABLE 5 Robustness check results for RAE on the recovery rate level.

(a) RAE in-sample $_{\mathrm{RA}}$

\begin{tabular}{cccccc}
\hline Specification & Bank 1 & Bank 2 & Bank 3 & Bank 4 \\
\hline 1 & 100 & 98.641 & 96.450 & 94.778 \\
& \multirow{2}{*}{2} & 100 & 98.575 & 96.225 & 94.611 \\
& \multirow{2}{*}{3} & - & $(0.469)$ & $(0.494)$ & $(0.612)$ \\
& 100 & 97.864 & 95.648 & 93.879 \\
& 4 & - & $(0.474)$ & $(0.494)$ & $(0.606)$ \\
& 100 & 97.826 & 95.576 & 93.984 \\
& - & $(0.473)$ & $(0.500)$ & $(0.618)$ \\
\hline
\end{tabular}

(b) RAE

\begin{tabular}{cccccc}
\hline Specification & Bank 1 & Bank 2 & Bank 3 & Bank 4 \\
\hline \multirow{2}{*}{1} & 100 & 99.440 & 96.700 & 95.121 \\
& \multirow{2}{*}{2} & 100 & 99.483 & 96.485 & 94.989 \\
& \multirow{2}{*}{3} & - & $(8.381)$ & $(7.310)$ & $(6.615)$ \\
& 100 & 98.778 & 95.916 & 94.264 \\
& - & $(8.516)$ & $(7.365)$ & $(6.573)$ \\
& 100 & 98.830 & 95.838 & 94.389 \\
& - & $(8.407)$ & $(7.290)$ & $(6.577)$ \\
\hline
\end{tabular}

RAE is calculated by (3.2). Standard deviations are reported in parentheses.

to the computational complexity of the likelihood function, too little recovery data in the sample might be an explanation for a higher number of outliers for the recovery rate estimates compared with the other models. Since such outliers have a higher loading in a quadratic measure like RMSE than for a measure based on the absolute value like RAE, the distribution of RMSE itself is more sensitive to these. Thus, a higher standard deviation of RMSEs, which itself is the square root of a quadratic measure, is likely to be caused by this connection.

The results for $\mathrm{RAE}_{\mathrm{RR}}^{\text {in-sample }}$ and $\mathrm{RAE}_{\mathrm{RR}}^{\text {out-of-sample }}$ presented in Table 3 on page 36 broadly confirm the results above. Relative to the results of Bank 1, the Heckman model performs best, followed by the Tobit approach and the OLS approach, which only performs a little better than the historical average. It is notable that in-sample the standard deviation of the RAEs increases with decreasing average RAE, while out-of-sample the result is the opposite.
TABLE 6 Results for RMSE

\begin{tabular}{c}
\hline Specification \\
\hline 1 \\
2 \\
3 \\
4 \\
\hline \\
\\
\hline Specification \\
1 \\
2 \\
3 \\
4
\end{tabular}

In order to check whether 1 that have a missing value $(62$ the study. Table 4 on page 3 this robustness check for RM unchanged. In absolute term. for Bank 1 rises on average, three banks. Relative to Banl for the whole data set, as Tab

\subsection{Portfolio level}

The results of the performan in Table $6 .{ }^{4}$ The probit appro yield almost identical RMSEs Tobit approach yields the wor: specifications. Specification 4 between Bank 2 and Bank 4

${ }^{4}$ Note that the portfolio loss rate $\mathrm{m}$ considered in this paper. This woul to capture the comovement of defa models.

Research Paper 
svery rate level.

\begin{tabular}{ll}
\hline ank 3 & Bank 4 \\
\hline 3.450 & 94.778 \\
$.490)$ & $(0.617)$ \\
$j .225$ & 94.611 \\
$3.494)$ & $(0.612)$ \\
$j .648$ & 93.879 \\
$3.494)$ & $(0.606)$ \\
$j .576$ & 93.984 \\
) $.500)$ & $(0.618)$ \\
\hline
\end{tabular}

\begin{tabular}{ll}
\hline ink 3 & Bank 4 \\
\hline i.700 & 95.121 \\
$.253)$ & $(6.517)$ \\
i.485 & 94.989 \\
$.310)$ & $(6.615)$ \\
i.916 & 94.264 \\
$.365)$ & $(6.573)$ \\
i.838 & 94.389 \\
$.290)$ & $(6.577)$ \\
\hline
\end{tabular}

es.

:tion, too little recovery data in ser of outliers for the recovery e such outliers have a higher measure based on the absolute ore sensitive to these. Thus, a the square root of a quadratic

ssented in Table 3 on page 36 ;ults of Bank 1, the Heckman and the OLS approach, which ;e. It is notable that in-sample :creasing average RAE, while
TABLE 6 Results for RMSE and RAE of the portfolio default rate.

(a) RMSEDR

\begin{tabular}{ccccc}
\hline Specification & Bank 1 & Bank 2 & Bank 3 & Bank 4 \\
\hline 1 & 0.000668 & 0.000668 & 0.000674 & 0.000669 \\
2 & 0.000679 & 0.000675 & 0.000680 & 0.000675 \\
3 & 0.000681 & 0.000676 & 0.000684 & 0.000677 \\
4 & 0.000684 & 0.000675 & 0.000683 & 0.000676 \\
\hline
\end{tabular}

(b) RAE

\begin{tabular}{crrrr}
\hline Specification & Bank 1 & Bank 2 & Bank 3 & Bank 4 \\
\hline 1 & 100 & 100.000 & 100.591 & 99.941 \\
2 & 100 & 99.256 & 99.837 & 99.192 \\
3 & 100 & 99.099 & 100.207 & 99.227 \\
4 & 100 & 98.668 & 99.652 & 98.746 \\
\hline
\end{tabular}

In order to check whether the results are data specific, we excluded all observations that have a missing value (62990 observations) for rating - rating $_{i t-1}$ and repeated the study. Table 4 on page 37 and Table 5 on the facing page present the results of this robustness check for RMSE and RAE. Qualitatively, the previous results remain unchanged. In absolute terms the data reduction has contrary effects. While RMSE for Bank 1 rises on average, it decreases for almost every specification of the other three banks. Relative to Bank 1, each of the other three banks performs better than for the whole data set, as Table 5 on the facing page shows.

\subsection{Portfolio level}

The results of the performance analysis for the portfolio default rate are presented in Table $6{ }^{4}$ The probit approach of Bank 2 and the Heckman approach of Bank 4 yield almost identical RMSEs, which are lower than for Bank 1 and Bank 3. Bank 3's Tobit approach yields the worst predictions of all four banks for the first three model specifications. Specification 4 shows a slightly higher RMSE $E_{D R}$ for Bank 1. The draw

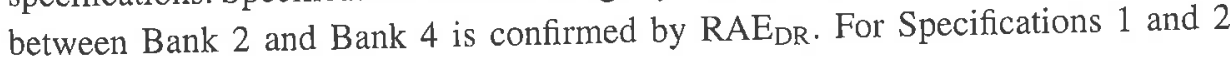

\footnotetext{
${ }^{4}$ Note that the portfolio loss rate may also be compared with the value-at-risk of the LGD models considered in this paper. This would require accounting for an unobservable systematic risk factor to capture the comovement of default and recovery processes. Bade et al (2011) introduce such models.
} 
TABLE 7 Results for RMSE and RAE of the portfolio loss rate.

TABLE 8 Robustness che

(a) RMSELR

\begin{tabular}{ccccc}
\hline Specification & Bank 1 & Bank 2 & Bank 3 & Bank 4 \\
\hline 1 & 0.000462 & 0.000616 & 0.000550 & 0.000463 \\
2 & 0.000466 & 0.000618 & 0.000554 & 0.000466 \\
3 & 0.000463 & 0.000626 & 0.000557 & 0.000465 \\
4 & 0.000470 & 0.000629 & 0.000560 & 0.000469 \\
\hline
\end{tabular}

(b) $\mathrm{RAE}_{\mathrm{LR}}$

\begin{tabular}{ccccr}
\hline Specification & Bank 1 & Bank 2 & Bank 3 & Bank 4 \\
\hline 1 & 100 & 136.607 & 120.479 & 100.912 \\
2 & 100 & 135.682 & 120.010 & 99.967 \\
3 & 100 & 137.819 & 121.082 & 100.214 \\
4 & 100 & 137.341 & 120.604 & 100.197 \\
\hline
\end{tabular}

the Heckman approach yields a lower value for $\mathrm{RAE}_{\mathrm{DR}}$ and for the remaining two specifications the probit approach is advantageous.

The results for the portfolio loss rate shown in Table 7 are much more widespread. Here, the simple prediction by historical average is the best predictor for future portfolio loss rates, followed closely by the Heckman approach of Bank 4. The Tobit approach performs rather poorly with a $20 \%$ worse loss estimation against the historical average, indicating that default and recovery process are not perfectly correlated. The worst performance is reached by Bank 2, with more than $35 \%$ fewer accurate loss rate predictions. Thus, an estimation of two separate models for PD and LGD followed by a calculation of the expected loss based on the parameters derived from both models is not suitable. It results in a high degree of misspecification, since the possible correlation between the processes is ignored.

We provide the same robustness check on the portfolio level as on the single borrower level. Table 8 on the facing page shows the results. Due to the data reduction, RMSE $_{D R}$ and $R M S E_{L R}$ deteriorate for all four banks. The draw between Bank 2 and Bank 4 concerning the default rate forecast switches to a marginal advantage for the probit approach. The portfolio loss rate predictions of Banks 2-4 relative to Bank 1 improve compared with the primary results. Yet the Heckman approach yields the best predictions if more explanatory variables than the rating grade are taken into consideration.

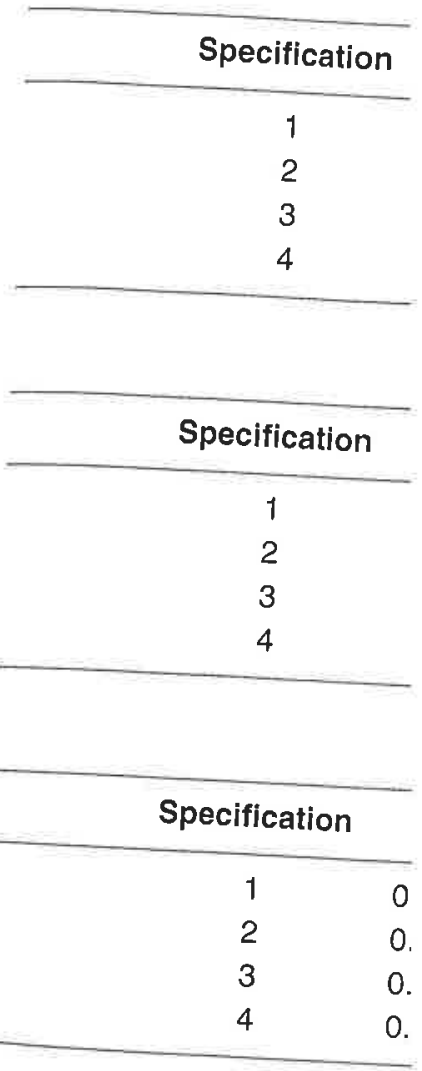

\begin{tabular}{c}
\hline Specification $\quad$ B \\
\hline 1 \\
2 \\
3 \\
4 \\
\hline
\end{tabular}

\section{CONCLUSION}

Various work in the literature on tributions suggesting a joint mo. of these quantities and the challe While many previous contributio

Rosearch Paper 
iss rate.

\begin{tabular}{ll}
\hline Bank 3 & Bank 4 \\
\hline .000550 & 0.000463 \\
.000554 & 0.000466 \\
.000557 & 0.000465 \\
.000560 & 0.000469 \\
\hline
\end{tabular}

\begin{tabular}{cr}
\hline Bank 3 & Bank 4 \\
\hline $\mid 20.479$ & 100.912 \\
$\mid 20.010$ & 99.967 \\
$\mid 21.082$ & 100.214 \\
$\mid 20.604$ & 100.197
\end{tabular}

$E_{D R}$ and for the remaining two

e 7 are much more widespread. le best predictor for future portıpproach of Bank 4. The Tobit ss estimation against the historess are not perfectly correlated. more than $35 \%$ fewer accurate rarate models for PD and LGD on the parameters derived from e of misspecification, since the

folio level as on the single borults. Due to the data reduction, The draw between Bank 2 and to a marginal advantage for the f Banks 2-4 relative to Bank 1 Heckman approach yields the the rating grade are taken into
TABLE 8 Robustness check results for RMSE and RAE on the portfolio level.

(a) RMSE

\begin{tabular}{ccccc}
\hline Specification & Bank 1 & Bank 2 & Bank 3 & Bank 4 \\
\hline 1 & 0.000874 & 0.000874 & 0.000878 & 0.000874 \\
2 & 0.000862 & 0.000859 & 0.000863 & 0.000859 \\
3 & 0.000875 & 0.000868 & 0.000874 & 0.000870 \\
4 & 0.000876 & 0.000867 & 0.000872 & 0.000868 \\
\hline
\end{tabular}

(b) RAE

\begin{tabular}{crrrr}
\hline Specification & Bank 1 & Bank 2 & Bank 3 & Bank 4 \\
\hline 1 & 100 & 100000 & 100306 & 99966 \\
2 & 100 & 99628 & 99988 & 99631 \\
3 & 100 & 99263 & 99804 & 99374 \\
4 & 100 & 98882 & 99366 & 98975 \\
\hline
\end{tabular}

(c) RMSE

\begin{tabular}{ccccc}
\hline Specification & Bank 1 & Bank 2 & Bank 3 & Bank 4 \\
\hline 1 & 0.000595 & 0.000777 & 0.000664 & 0.000599 \\
2 & 0.000587 & 0.000766 & 0.000652 & 0.000586 \\
3 & 0.000600 & 0.000782 & 0.000666 & 0.000595 \\
4 & 0.000591 & 0.000773 & 0.000658 & 0.000587 \\
\hline
\end{tabular}

(d) RAE $_{L R}$

\begin{tabular}{ccccc}
\hline Specification & Bank 1 & Bank 2 & Bank 3 & Bank 4 \\
\hline 1 & 100 & 131485 & 110730 & 100292 \\
2 & 100 & 131982 & 110707 & 99698 \\
3 & 100 & 132489 & 111229 & 99334 \\
4 & 100 & 133427 & 111760 & 99252 \\
\hline
\end{tabular}

\section{CONCLUSION}

Various work in the literature on default rates and recovery rates, as well as recent contributions suggesting a joint modeling of both variables, shows the high complexity of these quantities and the challenge involved in obtaining an accurate measurement. While many previous contributions focused on the qualitative and quantitative drivers 
of both variables, this paper compares the predictive performance of several modeling approaches. RMSEs and RAEs are calculated for four banks, with each bank using a different approach to forecast future defaults and losses. In order to check their contribution to the predictive power of each bank's approach, four different combinations of explanatory variables are investigated.

The results show that a disjunct consideration of default and recovery ignoring the high correlation between both quantities yields not only biased parameter estimates, but also a worse predictive power for future losses than the general approach applied by Bade et al (2011). Especially on the portfolio loss level, the relative inaccuracy is severe.

While the portfolio default rate estimates may not be considered as significantly differing among the four banks, the portfolio loss rate and the recovery rate of a single borrower are predicted best with the general model allowing default and recovery to be correlated. Nevertheless, the quick and dirty solution also yields a relatively accurate measure of the future portfolio loss rate.

Thus, accounting for the high correlation of default and recovery rates highlighted during past economic downturns - most recently by the global financial crisis - is a necessary condition for a suitable credit risk model. This paper provides further evidence that the model suggested by Pykhtin (2003) and adopted by Bade et al (2011) is a suitable model fulfilling this requirement.

\section{REFERENCES}

Acharya, V. V., Bharath, S. T., and Srinivasan, A. (2007). Does industry-wide distress affect defaulted firms? Evidence from creditor recoveries. Journal of Financial Economics 85(3), 787-821.

Altman, E. (2009). Default recovery rates and LGD in credit risk modeling and practice: an updated review of the literature and empirical evidence. Working Paper, Stern School of Business, New York University.

Bade, B., Rösch, D., and Scheule, H. (2011). Default and recovery risk dependencies in a simple credit risk model. European Financial Management 17(1), 120-144.

Bastos, J. A. (2010). Forecasting bank loans loss-given-default. Journal of Banking and Finance 34(10), 2510-2517.

Bellotti, T., and Crook, J. (2007). Modelling and predicting loss given default for credit cards. Working Paper, University of Edinburgh.

Bierens, H. J. (2004). The Tobit model. Working Paper, Pennsylvania State University. Bierens, H.J. (2007). Maximum likelihood estimation of Heckman's sample selection model. Working Paper, Pennsylvania State University.

Bruche, M., and González-Aguado, C. (2010). Recovery rates, default probabilities, and the credit cycle. Journal of Banking and Finance 34(4), 754-764.

Calabrese, R., and Zenga, M. (2010). Bank loan recovery rates: measuring and nonpara. metric density estimation. Journal of Banking and Finance 34(5), 903-911.
Carey, M. (1998). Credit risk in Caselli, S., Gatti, S., and Quı to systematic risk: new emp Research 34(1), 1-34.

Citron, D., Wright, M., Ball, R., from management buy-outs

Dermine, J., and de Carvalho, Journal of Banking and Fina

Duffie, D., and Singleton, K. (19 of Financial Studies 12(4), $6 i$

Duffie, D., Saita, L., and Wang stochastic covariates. Journa

Gordy, M., and Heitfield, E. (201 data are scarce. Working par Division of Research and Stal

Gordy, M., and Heitfield, E. (20 credit rating performance data

Grunert, J., and Weber, M. (200 dence for German companies. Hamerle, A., Liebig, T., and Ro 16(11), 77-82.

Heckman, J. J. (1979). Sample se 153-161.

Jarrow, R., and Turnbull, S. (199: credit risk. Journal of Finance 5

Jarrow, R., Lando, D., and Turnbe credit risk spreads. Review of $F$. Kupiec, P. H. (2008). A generalize Journal of Derivatives 15(3), 25 -

Leland, H. (1994). Corporate debi Journal of Finance 49(4), 1213Leland, H., and Toft, K. (1996). Of the term structure of credit sprea

Longstaff, F., and Schwartz, E. (199 rate debt. Journal of Finance 50 (.

Madan, D., and Unal, H. (1995). Pri Journal of Banking and Finance: McNeil, A., and Wendin, J. (2007). B of portfolio credit risk. Journal of $t$ Merton, R. C. (1974). On the pricing Jykhtinal of Finance 29(2), 449-47i Qi, M., and (2003). Unexpected reco Journal of Banking and Finance 3:
J., and Yane 
formance of several modeling sanks, with each bank using a 3. In order to check their con$h$, four different combinations

ault and recovery ignoring the y biased parameter estimates, I the general approach applied evel, the relative inaccuracy is

be considered as significantly nd the recovery rate of a single wing default and recovery to be Iso yields a relatively accurate

and recovery rates highlighted the global financial crisis - is 1. This paper provides further 3) and adopted by Bade et al

Joes industry-wide distress affect Journal of Financial Economics

dit risk modeling and practice: an э. Working Paper, Stern School of

7 recovery risk dependencies in a ment 17(1), 120-144.

i-default. Journal of Banking and

\} loss given default for credit cards.

Jennsylvania State University. eckman's sample selection model.

ry rates, default probabilities, and 7), 754-764.

ary rates: measuring and nonparazance $34(5), 903-911$.
Carey, M. (1998). Credit risk in private debt portfolios. Journal of Finance 53(4), 1363-1387 Caselli, S., Gatti, S., and Querci, F. (2008). The sensitivity of the loss given default rate to systematic risk: new empirical evidence on bank loans. Journal of Financial Services Research 34(1), 1-34.

Citron, D., Wright, M., Ball, R., and Rippington, F. (2003). Secured creditor recovery rates from management buy-outs in distress. European Financial Management 9(2), 141-161.

Dermine, J., and de Carvalho, C. N. (2006). Bank loan losses-given-default: a case study. Journal of Banking and Finance 30(4), 1219-1243.

Duffie, D., and Singleton, K. (1999). Modeling term structures of defaultable bonds. Review of Financial Studies 12(4), 687-720.

Duffie, D., Saita, L., and Wang, K. (2007). Multi-period corporate default prediction with stochastic covariates. Journal of Financial Economics 83(3), 635-665.

Gordy, M., and Heitfield, E. (2000). Estimating factor loadings when ratings performance data are scarce. Working paper, Board of Governors of the Federal Reserve System, Division of Research and Statistics.

Gordy, M., and Heitfield, E. (2002). Estimating default correlations from short panels of credit rating performance data. Working Paper, Federal Reserve Board.

Grunert, J., and Weber, M. (2009). Recovery rates of commercial lending: empirical evidence for German companies. Journal of Banking and Finance 33(3), 505-513.

Hamerle, A., Liebig, T., and Rosch, D. (2003). Benchmarking asset correlations. Risk 16(11), 77-82.

Heckman, J. J. (1979). Sample selection bias as a specification error. Econometrica 47(1), 153-161.

Jarrow, R., and Turnbull, S. (1995). Pricing derivatives on financial securities subject to credit risk. Journal of Finance 50(1), 53-85.

Jarrow, R., Lando, D., and Turnbull, S. (1997). A Markov model for the term structure of credit risk spreads. Review of Financial Studies 10(2), 481-523.

Kupiec, P. H. (2008). A generalized single common factor model of portfolio credit risk. Journal of Derivatives 15(3), 25-40.

Leland, H. (1994). Corporate debt value, bond covenants and optimal capital structure. Journal of Finance 49(4), 1213-1252.

Leland, H., and Toft, K. (1996). Optimal capital structure, endogeneous bankruptcy, and the term structure of credit spreads. Journal of Finance 51(3), 987-1019.

Longstaff, F., and Schwartz, E. (1995). A simple approach to valuing risky fixed and floating rate debt. Journal of Finance 50(3), 789-819.

Madan, D., and Unal, H. (1995). Pricing the risk of recovery in default with APR violation. Journal of Banking and Finance 27(6), 1001-1218.

McNeil, A., and Wendin, J. (2007). Bayesian inference for generalized linear mixed models of portfolio credit risk. Journal of Empirical Finance 14(2), 131-149.

Merton, R. C. (1974). On the pricing of corporate debt: the risk structure of interest rates. Journal of Finance 29(2), 449-470.

Pykhtin, M. (2003). Unexpected recovery risk. Risk 16(8), 74-78.

Qi, M., and Yang, X. (2009). Loss given default of high loan-to-value residential mortgages. Journal of Banking and Finance 33(5), 788-799. 
Qi, M., and Zhao, X. (2011). Comparison of modeling methods for loss given default. Journal of Banking and Finance, forthcoming.

Rösch, D., and Scheule, H. (2005). A multi-factor approach for systematic default and recovery risk. Journal of Fixed Income 15(2), 63-75.

Rösch, D., and Scheule, H. (2009). An unbiased approach for PD and recovery estimation. Working Paper, University of Hannover and The University of Melbourne.

Rösch, D., and Scheule, H. (2010). Downturn credit portfolio risk, regulatory capital and prudential incentives. International Review of Finance 10(2), 185-207.

Shumway, T. (2001). Forecasting bankruptcy more accurately: a simple hazard-rate model. Journal of Business 74(1), 101-124.
The Journal of Risk Model Val

\section{A practical anat risk charge moc}

\section{Marcus R. W. Martin}

University of Applied Sciences, I email: marcus.martin@h-da.de

\section{Helmut Lutz}

DekaBank, Hahnstrasse 55, 60 E email: helmut.lutz@deka.de

\section{Carsten S. Wehn}

DekaBank, Hahnstrasse 55, 605 email: wehn@gmx.de

This paper considers the d tal risk charge. We show $t$ t reasoning behind this. We s multistate credit risk mode credit risk modeling with ! charge and successively rea tory requirements. We analy factor reduction, nigration efficient semianalytical incr, the CRM. This analysis gives and thus into the models' ana plexity is highly relevant to $t$ applying the different approc

Marcus R. W. Martin is Professor of Applied Sciences, Darmstadt. Helmut Frankfurt. Carsten S. Wehn is head modeling team is responsible for devel risks, credit risks, liquidity risks and o responsible for validating the adequacy testing and economic capital models own and should not be cited as being described herein is claimed to be in act 